\title{
Effects Study of Early Weaning Time on the Growth and Development of Dairy Sheep Lamb
}

\author{
Ying Ma ${ }^{1,2}$, Zhong Zheng ${ }^{1,2}$, Liguo Zhang ${ }^{3}$, Yingjie Dou ${ }^{1,2}$, Urhan Bai ${ }^{1,2}$, Xin Liu ${ }^{4}$, Xiaoran Zhang ${ }^{1,2}$, \\ Xiaohu Su ${ }^{1,2}$, Li Zhang ${ }^{1,2, *}$ \\ ${ }^{1}$ The State Key Laboratory of Reproductive Regulation and Breeding of Grassland Livestock, Inner Mongolia University, Hohhot, \\ Inner Mongolia Autonomous Region, 010018, China. \\ ${ }^{2}$ College of Life Science, Inner Mongolia University, Hohhot, Inner Mongolia Autonomous Region, 010018, China. \\ ${ }^{3}$ Ulanqab Animal Husbandry Workstation, Ulanqab Agriculture and Animal Husbandry Bureau, Ulanqab, Inner Mongolia Auto- \\ nomous Region, 012000, China. \\ ${ }^{4}$ Mengtianran Animal Husbandary Technology Development Co. Ltd. Ulanqab, Inner Mongolia autonomous region, 012000, \\ China.
}

How to cite this paper: Ying Ma, Zhong Zheng, Liguo Zhang, Yingjie Dou, Urhan Bai, Xin Liu, Xiaoran Zhang, Xiaohu Su, Li Zhang. (2021) Extrusion Parameters Impact on Cooking Qualities of Plantain-Wheat Instant Noodles. International Journal of Food Science and Agriculture, 5(3), 411-420.

DOI: 10.26855/ijfsa.2021.09.011

Received: June 28, 2021

Accepted: July 22, 2021

Published: August 9, 2021

*Corresponding author: Li Zhang, The State Key Laboratory of Reproductive Regulation and Breeding of Grassland Livestock, Inner Mongolia University, Hohhot, Inner Mongolia Autonomous Region, 010018, China; College of Life Science, Inner Mongolia University, Hohhot, Inner Mongolia Autonomous Region, 010018, China.

Email: zhanglinmg@aliyun.com

\begin{abstract}
Appropriate early weaning (EW) technology can maximize the value of maternal sheep production without impact the normal growth and development of lambs. However, there is no mature EW technology for dairy sheep lambs. This study aimed to establish an appropriate EW technology for the crossbreed offspring of Dairy Meade (DM) sheep and Small-tailed Han (STH) sheep. The male lambs with similar birth weight were separated as four groups: three experimental groups (EW, $\mathrm{n}=6$ of each group) of 7, 15 and 25D weaning after birth which using restricted milk replacer (MR) and the control group ( $\mathrm{CON}, \mathrm{n}=8)$ which artificially-reared with breast milk. The results showed that there was no significant difference in growth performance among each group at D90. In terms of organ weight, except the heart weight EW7 was higher than CON ( $<<0.05)$, there was no significant difference between others $(p>0.05$ ). The routine analysis of blood showed that there was no significant difference in major components between EW and CON groups. Histological analysis of digestive system showed that there was no significant difference between EW groups and CON except the rumen papillae width of EW25. The results of rumen fermentation parameters showed that there was no significant difference in $\mathrm{pH}$ and microbial proteins (MCP) content between EW groups and CON. In total, Different weaning time did not significantly affect the growth and development of dairy sheep lambs. Early weaning at D7 is a better strategy for the improvement of financial value of maternal sheep.
\end{abstract}

\section{Keywords}

Early Weaning, Dairy Sheep, Lambs Growth

\section{Introduction}

The lambs were suckled with the mother until 2-3 months old under the traditional feeding. However, this would prolong the breeding cycle and impact the body recovery, and then reduce reproductive efficiency [1]. On the other hand, it would affect the healthy growth and development of lambs for the breast nursing cannot satisfy the nutritional requirement due to multiple fetuses or insufficient milk production of ewes [2].

The early weaning (EW) technology is an efficient way to solve these problems. A variety of EW options were employed worldwide. However, The EW may be an important stressor for lambs [3]. This stress can lead to declining 
health, changes in hormone levels, and poor growth rates [4]. So, appropriate EW strategy is necessary for modern animal husbandry. There is no 'best' age to wean, and lambs can be weaned at as early as 21D old. However, the study of Hu lambs showed that EW at 21D after birth may have a negative impact on lambs' performance based on a short-term study [5]. Another research showed that the use of milk replacer (MR) before 21D after birth could replace breast milk partly without affect the growth of lambs [6]. Serious research showed that the EW strategy was affected by breeds, nursing environment, nutrition and so on [7, 8].

The Small-tailed Han (STH) sheep is a Chinese local breed with both meat and fur coats and it is also known for its high fecundity. And it presents good adaptability for various climatic conditions. So it will be a nice female parent for Chinese dairy sheep breeding. However, the average milk yield (0.645 L/day) of STH ewes is lower then Katahdin (1.38 L/day) and Saint Croix (1.26 L/day) ewes with multiple-born lambs [9]. The DairyMeade (DM) sheep which derived from New Zealand, with high milk yield, is a suitable male parent for Chinese dairy sheep breeding. Previous we obtained the offspring through grading up strategy with the STH sheep as female parent and DM sheep as male parent. However, there was no mature rearing technique for lambs.

Studies on EW in ruminants have mainly focused on growth performance, blood physiological parameters and rumen development [10-12]. In present study, we aimed to establish an appropriate EW technology for the crossbreed offspring of DM and STH sheep through the combination of EW days of age, nutrition and nursing environment. The growth performance, blood physiological parameters, histological analysis of digestive system and rumen development of lambs were analyzed. It would provide a theoretical reference for the EW of dairy sheep lambs and supply technical assistance for dairy sheep rearing.

\section{Materials and methods}

Animal manipulations in this study including welfare, husbandry and experimental sampling were approved by the Animal Ethics Committee of Inner Mongolia University (Permit number: IMU-IACUC-2018-B78C). The humane animal care and handling procedures were followed throughout the experiment.

\subsection{Experimental Design, Feeding Management and Feed Intake}

Twenty-six male F1 lambs (5.07 $\pm 0.22 \mathrm{~kg}$ of birth weight, similar birth age) which crossbred with Small-Tailed Han (STH) sheep as female parent and DairyMeade (DM) sheep as male parent were selected. Six lambs of each EW group and eight of CON group. All of lambs were separated from their mothers at D7 after birth and housed in pens $(2.0 \times 1.5$ $\mathrm{m})$ every two lambs. The temperature of breeding house was $-4-30^{\circ} \mathrm{C}$. All lambs were supplied with the leymus chinensis from D7 and the concentrated feed from D30. The lambs of CON group were artificially-reared with breast milk to D60. The lambs of EW groups were artificially-reared with MR from D7 (EW7), D15 (EW15) and D25 (EW25) to D60. Four days were needed to use MR completely, 25\% percent of volume of MR was added every day. The MR was reconstituted at $200 \mathrm{~g} / \mathrm{L}$ of water and offered at a temperature of $-40^{\circ} \mathrm{C}$. Four times per day of feeding before D30 and followed three times per day till D60. The nutritious components of MR and concentrated feed were listed at Table 1. After D60, All lambs were weaned off liquid supplements and fed with solid fodder totally. The warm water $\left(10-20^{\circ} \mathrm{C}\right)$ was supplied anytime.

Table 1. Chemical composition (\% of DM) of the milk replacer (MR) and concentrated feed fed to lambs

\begin{tabular}{ccc}
\hline Item & Milk replacer (MR) & Concentrated feed \\
\hline $\mathrm{CP}, \%$ & 23 & 18 \\
$\mathrm{CF}, \%$ & 3 & 9 \\
$\mathrm{CA}, \%$ & 10 & 12 \\
$\mathrm{Ca}, \%$ & $0.6-1.5$ & $0.1-1.8$ \\
$\mathrm{TP}, \%$ & $0.5-1.2$ & 0.3 \\
$\mathrm{NaCl} \%$ & $0.1-1.2$ & $0.6-1.2$ \\
$\mathrm{Lys}, \%$ & 2.2 & 0.4 \\
\hline
\end{tabular}

CP: crude protein; CF: crude fibre; CA: crude ash; TP: total phosphorus.

At D0, 7, 30, 50, 70 and 90, the body weight, body height, body length and chest circumference of lambs were tested before first fed of morning and their daily gains were calculated.

\subsection{Slaughter experiment}

At D90, three to five lambs of each group were slaughtered. Firstly, the blood samples were collected in heparinized tubes by jugular venipuncture before slaughter. The blood sample was centrifuged at 3,500 g for $15 \mathrm{~min}$ at $4^{\circ} \mathrm{C}$ to separate serum, which was pipetted into $2 \mathrm{~mL}$ cryotubes and stored at $-20^{\circ} \mathrm{C}$ until subsequent analysis. Then after blood 
sampling, those lambs from each group were slaughtered. The live weight, slaughter weight, carcass weight and meat weight were measured and the meat percentage and dressing percent were calculated. The weight of heart, liver, spleen, lungs, kidneys, testicles, head and tail were measured.

\subsection{Blood Analysis}

The blood analyzer (PENTRA XL 80) was used for routine blood analysis. The biochemical analyzer (Cobas c 311) was used for analysis of serum physiological, biochemical and hormone enzymes. The concentrations of immunoglobulins (IgA, IgG, and IgM) were measured using respective enzyme-linked immunosorbent assay kits, which was processed in cooperation with Synthesis-bio Co. LTD. (Hohhot, Inner Mongolia autonomous region, China).

\subsection{Digestive System Morphology}

Postmortem, some of rumen, duodenum, jejunum and ileum was collected, emptied, washed with tap water and dried with paper towels. Histology slices were prepared followed by Carballo et al. [13]. Briefly, Three to five segments (approximately $5 \times 15 \mathrm{~mm}$ with $5 \mathrm{~mm}$ separation between each selected segment) were trimmed. The segments were dehydrated overnight through graded alcohols ( $70 \%, 95 \%$, and absolute alcohol) at ambient temperature, cleared in xylene and impregnated with Histosec pastilles under pressure at $60^{\circ} \mathrm{C}$. The segments were then embedded in wax, cut at $4-\mu \mathrm{m}$ thick. The cut sections were stained with a hematoxylin mixture and Eosin stain (HE staining).

Photomicrograph sections were taken of each slide with an optical microscope (Nikon, Japan). The photograph software was NIS-Element and Image $\mathrm{J}$ was used to measure. The length and width of the rumen papilla and the thickness of the muscle layer, the villi height, crypt depth and muscle thickness of the duodenum, jejunum and ileum were measured.

\subsection{Rumen fermentation parameters analysis}

Postmortem, the ruminal digesta sample was collected and $\mathrm{pH}$ value was measured immediately by a basic pen $\mathrm{pH}$ meter. The content of microbial protein (MCP) was estimated using the purine method [14].

\subsection{Statistical Analyses}

The data was summarized by Excel. The GraphPad Prism 8 was used for one-way analysis of variance (one-way ANOVA) and post-hoc comparisons to analyze the significance of the differences. The results are expressed as "mean value \pm standard deviation", the difference is judged to be significant based on $\mathrm{P}<0.05$, and the difference is extremely significant to $\mathrm{P}<0.01$.

\section{Results}

\subsection{EW strategy and analysis of growth traits}

The lambs were weaned at D7, 15, and 25 after birth and artificially-reared with MR till D60; the CON lambs were artificially-reared with breast milk till D60. Then all lambs were weaned off the liquid supplements and fed with solid fodder totally. The EW strategy was illustrated in Fig. 1A.

The body weight, daily weight gain, body height, body length and chest circumference of lambs were tested at D0, 7, 30, 50, 70 and 90 after birth. The body weight result showed that there was no significant difference between EW and CON groups $(P>0.05)$ (Fig. 1B). The daily weight gain varied between different groups after D30: at D30 50, the EW groups were significantly lower than CON group $(P<0.05)$; while at D51-70, the EW groups were similar or significantly higher than CON group; at D71-90, the EW and CON groups with no significant difference $(P>0.05)$ (Fig. 1C). Compared with CON, the body height of EW groups has no significant difference $(P>0.05)$ (Fig. 1D). The body length has no significant difference among different groups in total experimental time $(P>0.05)$ (Fig. 1E). The chest circumference has no significant difference among different groups at D90, while EW7 group was significantly higher than CON group at D30 $(P<0.05)$ (Fig. 1F). The results showed that our EW strategy did not affect the growth of dairy sheep male lambs.

\subsection{Analysis of carcass traits and organ development}

At D90, the lambs were slaughtered and carcass traits were analyzed. The body weight of EW7, EW15 EW 25 and CON were 29.95 $\pm 2.81,32.17 \pm 4.78,32.60 \pm 2.42$ and $31.35 \pm 3.13 \mathrm{~kg}$ and there was no significant difference between EW and CON groups $(P>0.05)$; the carcass weight were $14.34 \pm 1.57,15.87 \pm 2.23,16.57 \pm 0.95$ and $16.00 \pm 1.66 \mathrm{~kg}$ and also with no significant difference between EW and CON groups $(P>0.05)$ (Fig. 2A). The net meat percentage of EW7, EW15 EW 25 and CON were 32.00 $\pm 0.94,34.25 \pm 1.10,34.40 \pm 1.45$ and $26.48 \pm 17.67$ there was no significant difference between EW and CON groups $(P>0.05)$; while dressing percentage of EW7 group was significantly lower than CON 
group (47.85 \pm 2.18 vs $51.03 \pm 1.01, P<0.05)$; and the EW15 and ew25 were comparable with CON $(49.2 \pm 0.39$ and $50.86 \pm 1.00, P>0.05$ ) (Fig. 2B). The analysis of organ weight showed that the liver, spleen, lung, kidney, testis, head and tail were similar between EW and CON groups $(P>0.05)$, except that the heart weight of EW15 was significantly higher than CON group (245.83 \pm 9.67 vs $178.55 \pm 19.13, P<0.05)$ (Fig. 2 C). The results showed that our EW strategy did not affect the organ development of dairy sheep male lambs.

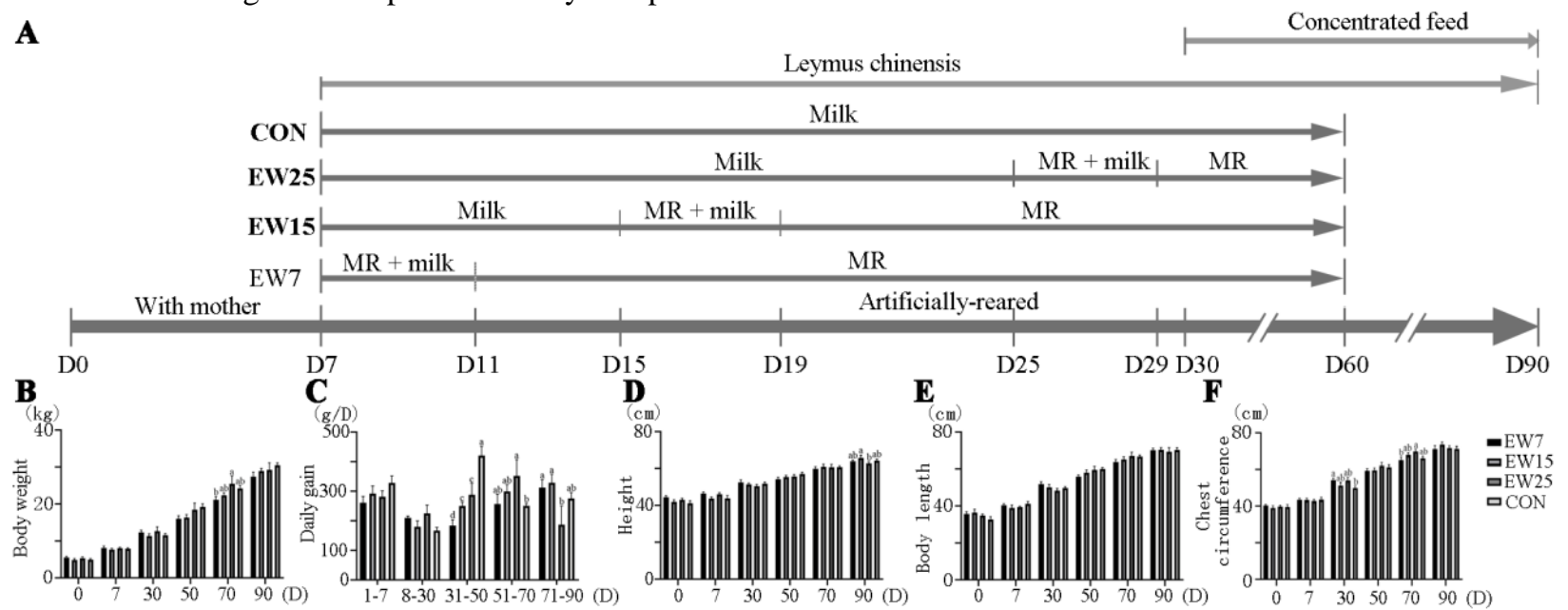

A: The schematic of study. B: The body weight of lambs from D0 to D90. C: The daily gain of lambs from D0 to D90. D: The height of lambs from D0 to D90. E: The body lenght of lambs from D0 to D90. F: The chest circumference of lambs from D0 to D90. EW7: weaning at D7 after birth. EW5: weaning at D15 after birth. EW25: weaning at D25 after birth. CON: Control (reared by breast milk). The adjacent letters represent significant differences $(p<0.05)$.

Figure 1. The schematic of study and the growth traits of lambs.

A

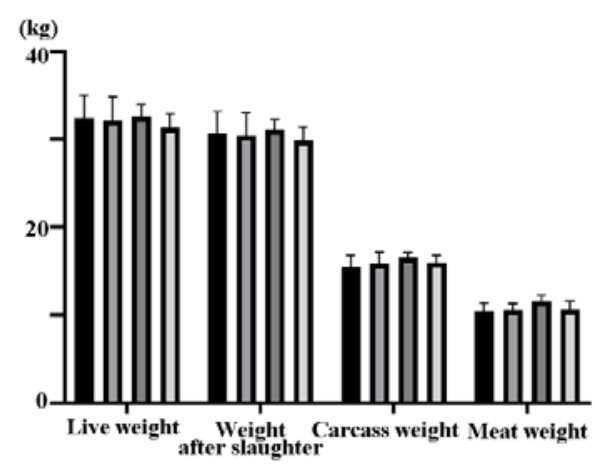

B $(\%)$

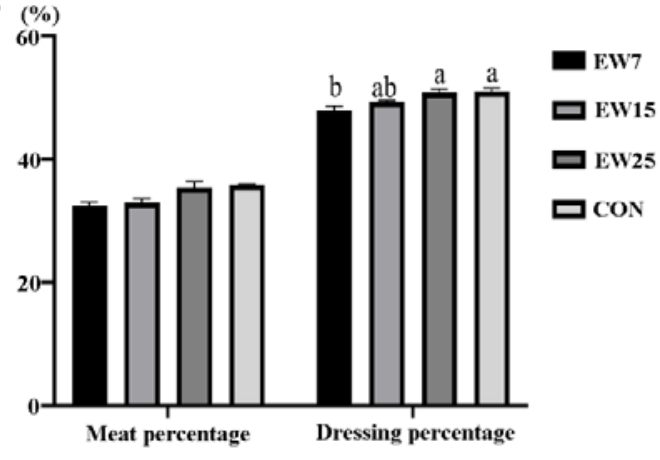

C

\begin{tabular}{|c|c|c|c|c|}
\hline \multirow{2}{*}{ Items } & \multicolumn{4}{|c|}{ Groups } \\
\hline & EW7 & EW15 & EW25 & $\mathrm{CON}$ \\
\hline Heart, $\mathrm{g}$ & $201.13 \pm 14.06^{\mathrm{ab}}$ & $245.83 \pm 9.67^{a}$ & $217.73 \pm 11.83^{\mathrm{ab}}$ & $178.55 \pm 19.13^{b}$ \\
\hline Liver, g & $612.03 \pm 49.76$ & $627.9 \pm 91.72$ & $532.23 \pm 28.42$ & $618.23 \pm 47.28$ \\
\hline Spleen, $\mathrm{g}$ & $50.75 \pm 5.21$ & $61.37 \pm 4.65$ & $55.8+3.65$ & $63.4 \pm 9.01$ \\
\hline Lungs, $\mathrm{g}$ & $613.53 \pm 52.05$ & $585.97 \pm 100.72$ & $514.13+33.81$ & $616.5 \pm 26.97$ \\
\hline Kidney (Contain fat), $g$ & $197.25 \pm 19.36$ & $217.07 \pm 30.26$ & $197.2 \pm 19.39$ & $267.43 \pm 52.03$ \\
\hline Kidney (No fat), $\mathrm{g}$ & $109.53 \pm 7.16$ & $119.03 \pm 10.81$ & $113.13+3.83$ & $122.6 \pm 10.48$ \\
\hline Testis, $\mathrm{g}$ & $122.23 \pm 10.37^{\mathrm{b}}$ & $217.27 \pm 38.56^{\mathrm{a}}$ & $185.57 \pm 16.2^{\mathrm{ab}}$ & $179.80 \pm 20.93^{\mathrm{ab}}$ \\
\hline Head, kg & $1.85 \pm 0.09$ & $1.87 \pm 0.07$ & $1.93 \pm 0.18$ & $1.94 \pm 0.10$ \\
\hline Tail, g & $139.90 \pm 15.91^{\mathrm{b}}$ & $135.97 \pm 19.81^{\mathrm{b}}$ & $246.43 \pm 29.02^{\mathrm{a}}$ & $199.57 \pm 36.16^{\mathrm{ab}}$ \\
\hline
\end{tabular}

A: The live and slaughter weight. B: The meat and dress percentage. C: The organ weight. Data presented are average means and SEM. EW7: weaning at D7 after birth. EW5: weaning at D15 after birth. EW25: weaning at D25 after birth. CON: Control (reared by breast milk). The adjacent letters represent significant differences $(\mathrm{p}<0.05)$.

Figure 2. The carcass and organ traits of lambs at D90. 


\subsection{Analysis of blood and serum examination}

The blood routine examination showed that there were no significant difference of LYM (lymphocyte), MON (monocyte count), RBC (red blood cell) and BAS (basophilic granulocyte) between EW and CON groups $(P>0.05)$; while the WBC (white blood cell) of EW15 was significantly lower than CON group (6.30 \pm 0.72 vs $10.78 \pm 0.85, P<0.05)$ and the HBG (hemoglobin) of EW25 was significantly higher than CON group (133.33 \pm 2.03 vs $121.75 \pm 3.90$ ) (Table 2).

Table 2. Blood routine examination of lambs at D90

\begin{tabular}{|c|c|c|c|c|}
\hline \multirow{2}{*}{ Items } & \multicolumn{4}{|c|}{ Groups } \\
\hline & EW7 & EW15 & EW25 & CON \\
\hline WBC, $\times 10^{9} / \mathrm{L}$ & $8.06 \pm 0.19^{\mathrm{ab}}$ & $6.30 \pm 0.72^{b}$ & $11.97 \pm 3.04^{\mathrm{a}}$ & $10.78 \pm 0.85^{\mathrm{a}}$ \\
\hline $\mathrm{LYM} \#, \times 10^{9} / \mathrm{L}$ & $0.26 \pm 0.04$ & $0.20 \pm 0.01$ & $0.33 \pm 0.07$ & $0.35 \pm 0.05$ \\
\hline MON\#, $\times 10^{9} / \mathrm{L}$ & $0.50 \pm 0.03$ & $0.43 \pm 0.03$ & $0.67 \pm 0.19$ & $0.70 \pm 0.14$ \\
\hline $\mathrm{RBC}, \times 10^{12} / \mathrm{L}$ & $10.22 \pm 0.24$ & $10.43 \pm 0.09$ & $10.37 \pm 0.67$ & $9.6 \pm 0.45$ \\
\hline BAS\#, $\times 10^{9} / \mathrm{L}$ & $0.07 \pm 0.01^{\mathrm{b}}$ & $0.10 \pm 0.02^{\mathrm{ab}}$ & $0.22 \pm 0.09^{\mathrm{a}}$ & $0.12 \pm 0.01^{\mathrm{ab}}$ \\
\hline BAS $\%, \times 10^{9} / \mathrm{L}$ & $0.86 \pm 0.05^{\mathrm{b}}$ & $1.57 \pm 0.12^{\mathrm{a}}$ & $1.60 \pm 0.40^{\mathrm{a}}$ & $1.10 \pm 0.04^{\mathrm{ab}}$ \\
\hline HGB, g/dL & $120.40 \pm 2.14^{\mathrm{b}}$ & $123.33 \pm 2.33^{\mathrm{b}}$ & $133.33 \pm 2.03^{\mathrm{a}}$ & $121.75 \pm 3.90^{\mathrm{b}}$ \\
\hline
\end{tabular}

WBC: white blood cell; LYM: lymphocyte; MON: monocyte count; BAS: basophilic granulocyte; RBC: red blood cell; HBG: hemoglobin. The adjacent letters represent significant differences $(\mathrm{p}<0.05)$.

The biochemical of serum showed that the GLU (blood glucose) of EW25 was significantly lower than CON group (5.42 \pm 0.39 vs 7.66 $\pm 0.83, P<0.05$ ); the HDL-C (high density lipoprotein cholesterol) of EW25 was significantly higher than CON group (1.14 \pm 0.07 vs $0.95 \pm 0.04, P<0.05)$; the $\mathrm{CO}_{2}-\mathrm{L}$ (bicarbonate) of EW15 and EW25 was significantly lower than CON group (19.73 $\pm 0.23,21.87 \pm 2.53$ vs $26.20 \pm 0.80, P<0.05)$; the CREJ (creatinine) of EW7 was significantly lower than CON group (55.40 \pm 3.03 vs $65.00 \pm 3.24, P<0.05$ ); and the TP (total protein), ALB(albumin), $\mathrm{CHOL}_{2}$ (cholesterol), LACT (lactic acid), TRIGL(triacylglycerol) and UREAL were no significant difference between EW and CON groups (Table 3).

Table 3. Serum biochemical parameter of lambs at D90

\begin{tabular}{|c|c|c|c|c|}
\hline \multirow{2}{*}{ Itens } & \multicolumn{4}{|c|}{ Groups } \\
\hline & EW7 & EW15 & EW25 & CON \\
\hline GLU, mmol/L & $5.92 \pm 0.58^{\mathrm{ab}}$ & $6.68 \pm 0.60^{\mathrm{ab}}$ & $5.42 \pm 0.39^{b}$ & $7.66 \pm 0.83^{\mathrm{a}}$ \\
\hline $\mathrm{TP}, \mathrm{g} / \mathrm{L}$ & $65.1 \pm 1.44$ & $64.73 \pm 1.2$ & $69.13 \pm 0.85$ & $68.28 \pm 2.97$ \\
\hline ALB, g/L & $35.6 \pm 1.06$ & $36.43 \pm 0.09$ & $37.23 \pm 1.65$ & $35.40 \pm 1.04$ \\
\hline HDL-C, mmol/L & $0.91 \pm 0.04^{\mathrm{b}}$ & $1.02 \pm 0.04^{\mathrm{ab}}$ & $1.14 \pm 0.07^{\mathrm{a}}$ & $0.95 \pm 0.04^{\mathrm{b}}$ \\
\hline LDL-C, mmol/L & $0.60 \pm 0.07$ & $0.75 \pm 0.05$ & $0.74 \pm 0.01$ & $0.71 \pm 0.09$ \\
\hline $\mathrm{CO}_{2}-\mathrm{L}, \mathrm{mmol} / \mathrm{L}$ & $23.54 \pm 1.00^{\mathrm{ab}}$ & $19.73 \pm 0.23^{\mathrm{b}}$ & $21.87 \pm 2.53^{b}$ & $26.20 \pm 0.80^{\mathrm{a}}$ \\
\hline $\mathrm{CHOL}_{2}, \mathrm{mmol} / \mathrm{L}$ & $1.38 \pm 0.09^{b}$ & $1.58 \pm 0.05^{\mathrm{ab}}$ & $1.66 \pm 0.06^{\mathrm{a}}$ & $1.47 \pm 0.11^{\mathrm{ab}}$ \\
\hline $\mathrm{LACT}, \mathrm{mmol} / \mathrm{L}$ & $5.98 \pm 1.05$ & $8.34 \pm 1.49$ & $6.67 \pm 1.39$ & $5.94 \pm 0.79$ \\
\hline TRIGL, mmol/L & $0.34 \pm 0.07$ & $0.32 \pm 0.03$ & $0.35 \pm 0.04$ & $0.35 \pm 0.01$ \\
\hline UREAL, mmol/L & $8.82 \pm 1.37$ & $8.27 \pm 0.23$ & $8.70 \pm 1.55$ & $8.90 \pm 1.02$ \\
\hline $\mathrm{CREJ}, \mu \mathrm{mol} / \mathrm{L}$ & $55.40 \pm 3.03^{b}$ & $60.33 \pm 2.40^{\mathrm{ab}}$ & $56.67 \pm 4.26^{\mathrm{ab}}$ & $65.00 \pm 3.24^{\mathrm{a}}$ \\
\hline
\end{tabular}

GLU: Blood glucose; TP: total protein; ALB: albumin; HDL-C: high density lipoprotein cholesterol; LDL-C: low density lipoprotein cholesterol; $\mathrm{CO}_{2}$-L: bicarbonate; CHOL2: cholesterol; TRIGL = triacylglycerol; CREJ =creatinine. The adjacent letters represent significant differences ( $<<0.05$ ).

The enzymes analysis of serum showed that the AST (Aspartate aminotransferase), ALT (Alanine aminotransferase), CK (creatine kinase), ALP (Alkaline phosphatase), LDH-L (lactic dehydrogenase), CHE (cholinesterase) and LIPC (lipase) were no significant difference between EW and CON groups except that the EW15 of AMY ( $\alpha$-amylase) was 
significantly lower than CON group $(10.17 \pm 1.10$ vs $19.28 \pm 4.36, P<0.05)$ (Table 4).

Table 4. The serum enzymes of lambs at D90

\begin{tabular}{ccccc}
\hline \multirow{2}{*}{ Itens } & \multicolumn{4}{c}{ Groups } \\
\cline { 2 - 5 } & EW7 & EW15 & EW25 & CON \\
\hline AST, U/L & $171.42 \pm 29.17$ & $259.27 \pm 101.47$ & $128.17 \pm 8.48$ & $189.48 \pm 30.82$ \\
ALT, U/L & $15.98 \pm 1.32$ & $18.60 \pm 1.50$ & $17.53 \pm 0.68$ & $16.80 \pm 2.21$ \\
CK, U/L & $578.80 \pm 133.2$ & $670.33 \pm 105.80$ & $425.33 \pm 37.12$ & $977.00 \pm 272.72$ \\
AMY, U/L & $13.26 \pm 0.99^{\mathrm{ab}}$ & $10.17 \pm 1.10^{\mathrm{b}}$ & $16.93 \pm 2.53^{\mathrm{ab}}$ & $19.28 \pm 4.36^{\mathrm{a}}$ \\
ALP, U/L & $694.00 \pm 58.87$ & $779.00 \pm 123.75$ & $610.00 \pm 147.55$ & $720.75 \pm 34.59$ \\
LDH-L, U/L & $946.60 \pm 161.83$ & $773.67 \pm 138.77$ & $626.33 \pm 67.91$ & $937.50 \pm 78.63$ \\
CHE, U/L & $93.40 \pm 7.18$ & $92.33 \pm 6.12$ & $111.33 \pm 13.64$ & $94.25 \pm 6.61$ \\
LIPC, U/L & $31.40 \pm 5.42$ & $33.20 \pm 0.99$ & $24.17 \pm 6.57$ & $33.98 \pm 3.28$ \\
\hline
\end{tabular}

AST: Aspartate aminotransferase; ALT: Alanine aminotransferase; AMY: $\alpha$-amylase; ALP: Alkaline phosphatase; LDH-L: lactic dehydrogenase. The adjacent letters represent significant differences $(\mathrm{p}<0.05)$.

Furthermore, the immune globulin of serum was analyzed. The result showed that the EW25 of IgA was significantly higher than CON group (656.98 \pm 15.76 vs $392.27 \pm 4.75, P<0.01$ ); the EW25 of IgM was also significantly higher than CON group ( $3435.00 \pm 151.55$ vs $2047.50 \pm 66.34, P<0.01$ ); while the level of IgG with no significant difference between EW and CON groups (Table 5).

Table 5. The serum immune globulins of lambs at D90

\begin{tabular}{ccccc}
\hline \multirow{2}{*}{ Items } & \multicolumn{4}{c}{ Groups } \\
\cline { 2 - 5 } & EW7 & EW15 & EW25 & CON \\
\hline IgA,$\mu \mathrm{g} / \mathrm{mL}$ & $407.19 \pm 30.45^{\mathrm{c}}$ & $462.19 \pm 80.53^{\mathrm{c}}$ & $656.98 \pm 15.76^{\mathrm{a}}$ & $392.27 \pm 4.75^{\mathrm{c}}$ \\
IgM, $\mu \mathrm{g} / \mathrm{mL}$ & $2227.50 \pm 113.10^{\mathrm{c}}$ & $2855.83 \pm 614.85^{\mathrm{c}}$ & $3435.00 \pm 151.55^{\mathrm{a}}$ & $2047.50 \pm 66.34^{\mathrm{c}}$ \\
IgG, $\mathrm{mg} / \mathrm{mL}$ & $81.17 \pm 3.54$ & $80.17 \pm 7.91$ & $84.85 \pm 2.70$ & $75.99 \pm 2.91$ \\
\hline
\end{tabular}

The spaced letters represent significant differences $(\mathrm{p}<0.01)$.

Serious data showed that the EW7 was more similar with CON group at blood examination.

\subsection{Analysis of histological of digestive system and rumen fermentation parameters}

The morphology of rumen, duodenum, jejunum and ileum were analyzed by HE (hematoxylin-eosin) staining at D90 (Fig. 3). The rumen papillae width of EW25 is significantly lower than CON group $(P<0.05)$, while there were no significant differences of papillae length and muscle layers thickness between EW and CON groups $(P>0.05)($ Fig. 3A-H, Fig. S1). About the duodenum, there were no significant differences of muscle layers thickness, villus height, crypt depth and V $\backslash C$ ratio between EW and CON groups $(P>0.05)$ (Fig. 3I-L, Fig. S2). About the jejunum, there were also no significant differences of muscle layers thickness, villus height, crypt depth and V\C ratio between EW and CON groups $(P>0.05)$ (Fig. 3M-P, Fig. S3). For the villus height crypt depth of ileum, the EW groups were significantly higher than CON group $(P<0.05)$, while the muscle layers thickness, and $V \backslash C$ rate were no significant differences $(P>0.05)$ (Fig. 3Q-T, Fig. S4).

At last, the rumen fermentation parameters were analyzed. The results showed that the $\mathrm{pH}$ and MCP were no significant difference between EW and CON groups (Table 6).

Table 6. The rumen fermentation parameters of lambs at D90

\begin{tabular}{ccccc}
\hline \multirow{2}{*}{ Items } & \multicolumn{3}{c}{ Groups } \\
\cline { 2 - 5 } & EW7 & EW15 & EW25 & CON \\
\hline $\mathrm{pH}$ & $6.17 \pm 0.12$ & $6.81 \pm 0.14$ & $6.45 \pm 0.90$ & $6.55 \pm 0.22$ \\
$\mathrm{MCP}, \mathrm{mg} / \mathrm{ml}$ & $2.70 \pm 0.11$ & $2.29 \pm 0.21$ & $2.47 \pm 0.03$ & $2.83 \pm 0.16$ \\
\hline
\end{tabular}

In total, these results showed that EW at D7 did not affect the development of digestive system. 


\section{Discussion}

In this study, the EW time of dairy sheep male lamb was determined. Through the comprehensively evaluation of growth, blood parameters, digestive system and organ development, we think that EW at D7 after birth could maximize the value of maternal sheep production without impact the normal growth and development of lambs. A research showed that the lambs were artificially fed with milk replacer and starter feed from D8, may not affect its growth[15]. At the first week, the sufficient ingestion of colostrum could help lambs to establish initial digestive and immune function.
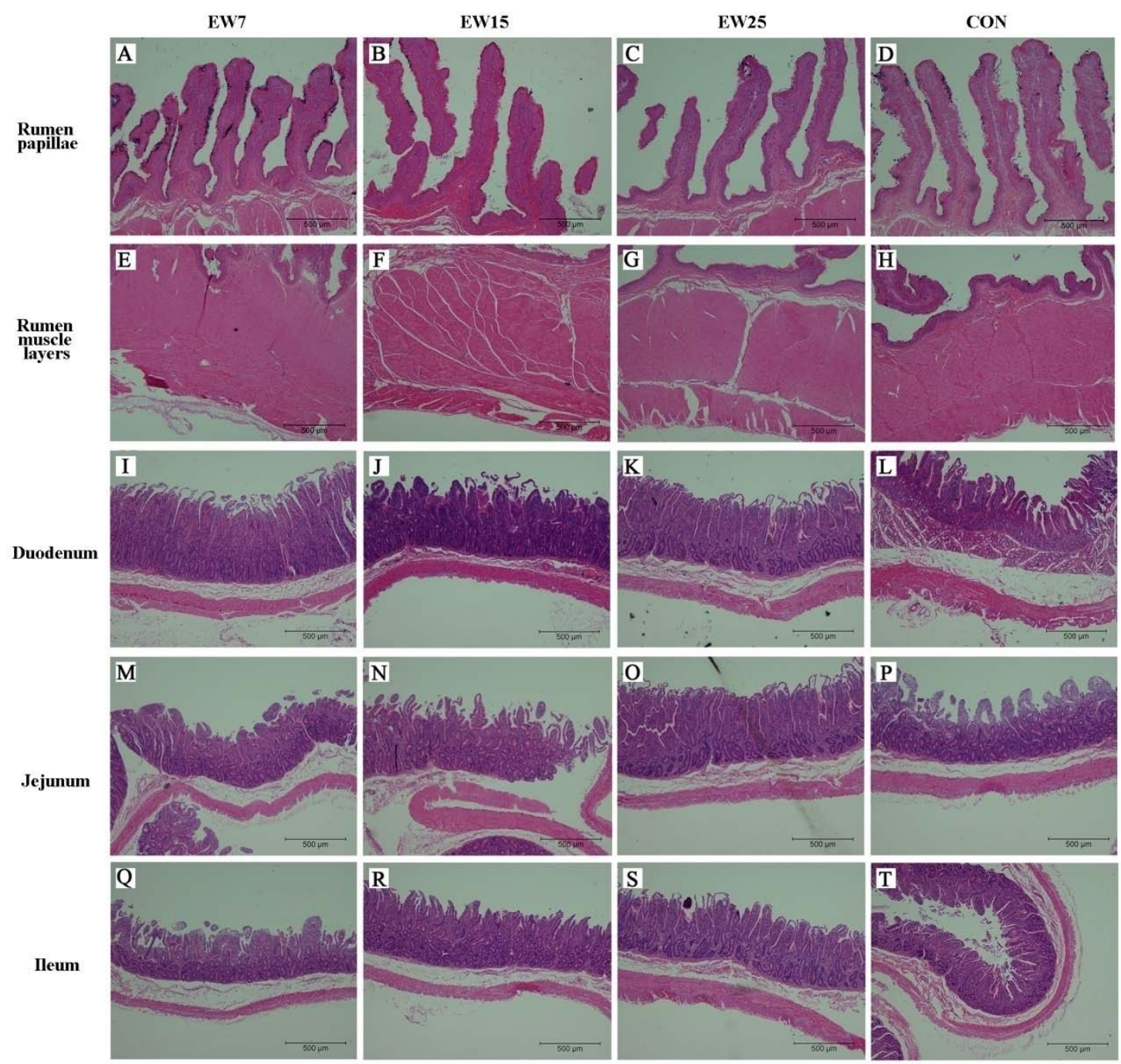

(A-D): Rumen papillae. (E-H): Rumen muscle layers. (I-L): Duodenum. (M-P): Jejunum. (Q-T): Ileum. EW7: weaning at D7 after birth. EW5: weaning at D15 after birth. EW25: weaning at D25 after birth. CON: Control (reared by breast milk).

Figure 3. The morphology of digestive system of lambs at D90.

The supplement selection is crucial for the health of EW lambs. In the EW research of Hu lambs, which were supplemented with starter at D7 after birth, but the growth of EW group was restricted and the diarrhea rate increased [5]. In McCoard et al.'s research, the MR was supplemented at D7 after birth and weaned off MR by 4 or 6 wks did not compromise lambs' growth [6]. But the study by Santos et al showed that the existence of long-term effects caused by early feed restriction with negative consequences on live body weight and reproductive traits of replacement ewe lambs [16]. In fact, we initial fed with two type of MR and one of MR would result diarrhea for most of lambs. The supplementation of live yeast based feed additive has a possible positive impact on lamb gut development and digestive efficiency [15].

In this study, the daily weight gain of D31-D50 data showed that EW groups were significantly lower than CON group, while there was obvious drop after D51. This is because of the nutrient transformation from breast milk to feed and the lambs have stress. The heavy lambs were more resilient than light lambs after weaning [17]. Therefore, the 
weaning as early as possible may reduce the stress of lamb and the loss of maternal nutrition. In addition, we found that the heart weight of EW15 group was significantly higher than CON group. Heart weight is dependent on sex, age, height, and weight [18]. It may be caused by the relative higher height of EW15 group and not pathological phenotype.

The WBC is one of the indispensable and important components of the body's immunity, which participates in the body's cellular immune process [19]. Under normal physiological conditions, the total number of WBC reflects the body's comprehensive immune response capabilities [20]. In this study, the count of WBC of EW15 group was significantly lower than CON group. Correspondingly, the basophils count of EW7 group was relative lower than others. Basophils are functionally closely related to mast cells, which all of them express the IgE receptor and rapidly release preformed mediator from intracellular stores upon IgE-mediated activation [21]. It seemed that EW may hurt the immunity of lambs. But the serum immunoglobulin assay showed that there was similar level between EW and CON groups. In total, EW has little harm for lamb's immunity.

The glucose of blood comes from the absorption of carbohydrates and liver glycogen and its concentration reflects a dynamic balance between sugar production and tissue consumption in the body [22]. The increase of glucose can enhance the function of adrenal cortex hormones and glucagon, and resist the influence of adverse factors such as cold and stress [23]. There was relative low concentration of blood glucose in EW groups, which indicated that it may less resistant than CON group at D90.

The importance of knowing creatinine levels in the human body is related to the possible association with renal, muscular and thyroid dysfunction [24]. High level of creatinine in blood may be associated with renal insufficiency. Our study showed that lower level of creatinine in EW groups, which indicated that it may have better development of renal.

\section{Conclusion}

In conclusion, this study showed that weaning at D7 after birth by feed with MR could ensure the healthy growth of dairy sheep lambs. These findings can provide a theoretical reference for the EW of dairy sheep lambs and supply technical assistance for dairy sheep rearing. Additionally, future studies should consider the female lambs' health in the lifespan and potential effects such as fertility and milk yield.

\section{Authors' contribution}

Li Zhang, Xiaohu Su conceived and designed the experiments; Ying Ma, Zhong Zheng, Liguo Zhang, Yingjie Dou, Urhan Bai, Xiaoran Zhang performed the experiments; Ying Ma, Zhong Zheng analyzed and interpreted the data; Li Zhang contributed reagents, materials, analysis tools or data; Ying Ma, Xiaohu Su wrote the paper.

\section{Acknowledgements}

This work was funded by the Major Science and Technology project of Inner Mongolia Autonomous Region of China (30900-5173910) and the Independent project of The State Key Laboratory of Reproductive Regulation and Breeding of Grassland Livestock of Inner Mongolia University of China (SKL-IT-201811). We owe many thanks to Monterra Animal Husbandary Technology Development Co. Ltd (Ulanqab, Inner Mongolia autonomous region, China) for the supply of place and animals. We owe many thanks to Synthesis-bio Co. LTD. (Hohhot, Inner Mongolia autonomous region, China) for the assay of immune globulin.

\section{Compliance with ethical standards}

Ethical issues: Animal manipulations in this study including welfare, husbandry and experimental sampling were approved by the Animal Ethics Committee of Inner Mongolia University (Permit number: IMU-IACUC-2018-B78C). The humane animal care and handling procedures were followed throughout the experiment.

Conflict of interest: The authors declare that they have no conflict of interest.

\section{References}

[1] David, I., Bouvier, F., Ricard, E., Ruesche, J., and Weisbecker, J. L. (2014). Feeding behaviour of artificially reared Romane lambs. Animal: An International Journal of Animal Bioscience, 8, 982-990. http://dx.doi.org/10.1017/s1751731114000603.

[2] Li, C., Wang, W., Liu, T., Zhang, Q., Wang, G., Li, F., Li, F., Yue, X., and Li, T. (2018). Effect of Early Weaning on the Intestinal Microbiota and Expression of Genes Related to Barrier Function in Lambs. Frontiers in Microbiology, 9, 1431. http://dx.doi.org/10.3389/fmicb.2018.01431.

[3] Orgeur, P., Bernard, S., Naciri, M., Nowak, R., Schaal, B., and Lévy, F. (1999). Psychobiological consequences of two different weaning methods in sheep. Reproduction, Nutrition, Development, 39, 231-244. http://dx.doi.org/10.1051/rnd:19990208.

[4] Farshim, P., Walton, G., Chakrabarti, B., Givens, I., Saddy, D., Kitchen, I., Jonathan, R. S., and Bailey, A. (2016). Maternal 
Weaning Modulates Emotional Behavior and Regulates the Gut-Brain Axis. Scientific Reports, 6, 21958. http://dx.doi.org/10.1038/srep21958.

[5] Wang, S., Ma, T., Zhao, G., Zhang, N., Tu, Y., Li, F., Cui, K., Bi, Y., Ding, H., and Diao, Q. (2019). Effect of Age and Weaning on Growth Performance, Rumen Fermentation, and Serum Parameters in Lambs Fed Starter with Limited Ewe-Lamb Interaction. Animals: An Open Access Journal from MDPI, 9. http://dx.doi.org/10.3390/ani9100825.

[6] McCoard, S. A., Cristobal-Carballo, O., Knol, F. W., Heiser, A., Khan, M. A., Hennes, N., Johnstone, P., Lewis, S., and Stevens, D. R. (2020). Impact of early weaning on small intestine, metabolic, immune and endocrine system development, growth and body composition in artificially reared lambs. Journal of Animal Science, 98. http://dx.doi.org/10.1093/jas/skz356.

[7] Bindon, B. M. (1984). Reproductive biology of the Booroola Merino sheep. Australian Journal of Biological Sciences, 37, 163-189. http://dx.doi.org/10.1071/bi9840163.

[8] Talafha, A. Q. and Ababneh, M. M. (2011). Awassi sheep reproduction and milk production: review. Tropical Animal Health and Production, 43, 1319-1326. http://dx.doi.org/10.1007/s11250-011-9858-5.

[9] Wang, J., Zhou, H., Hickford, J. G. H., Hao, Z., Shen, J., Luo, Y., Hu, J., Liu, X., and Li, S. (2020). Comparison of the Transcriptome of the Ovine Mammary Gland in Lactating and Non-lactating Small-Tailed Han Sheep. Frontiers in Genetics, 11, 472. http://dx.doi.org/10.3389/fgene.2020.00472.

[10] Carroll, J. A., Arthington, J. D., and Chase, C. C., Jr. (2009). Early weaning alters the acute-phase reaction to an endotoxin challenge in beef calves. Journal of Animal Science, 87, 4167-4172. http://dx.doi.org/10.2527/jas.2009-2016.

[11] Liu, J., Bian, G., Sun, D., Zhu, W., and Mao, S. (2017). Starter Feeding Supplementation Alters Colonic Mucosal Bacterial Communities and Modulates Mucosal Immune Homeostasis in Newborn Lambs. Frontiers in Microbiology, 8, 429. http://dx.doi.org/10.3389/fmicb.2017.00429.

[12] Lambertz, C., Farke-Röver, A., Moors, E., and Gauly, M. (2015). Effects of castration and weaning conducted concurrently or consecutively on behaviour, blood traits and performance in beef calves. Animal: An International Journal of Animal Bioscience, 9, 122-129. http://dx.doi.org/10.1017/s1751731114002080.

[13] Carballo, O. C., Khan, M. A., Knol, F. W., Lewis, S. J., Stevens, D. R., Laven, R. A., and McCoard, S. A. (2019). Impact of weaning age on rumen development in artificially reared lambs1. Journal of Animal Science, 97, 3498-3510. http://dx.doi.org/10.1093/jas/skz148.

[14] Makkar, H. P. and Becker, K. (1999). Purine quantification in digesta from ruminants by spectrophotometric and HPLC methods. The British Journal of Nutrition, 81, 107-112.

[15] Chaucheyras-Durand, F., Ameilbonne, A., Auffret, P., Bernard, M., Mialon, M. M., Dunière, L., and Forano, E. (2019). Supplementation of live yeast based feed additive in early life promotes rumen microbial colonization and fibrolytic potential in lambs. Scientific Reports, 9, 19216. http://dx.doi.org/10.1038/s41598-019-55825-0.

[16] Santos, A., Giráldez, F. J., Valdés, C., Trevisi, E., Lucini, L., Frutos, J., and Andrés, S. (2018). Milk replacer restriction during early life impairs the live body weight and progesterone patterns of ewe lambs during the replacement period. Journal of Dairy Science, 101, 8021-8031. http://dx.doi.org/10.3168/jds.2018-14648.

[17] Keegan, J. D., Good, B., Hanrahan, J. P., Lynch, C., de Waal, T., and Keane, O. M. (2018). Live weight as a basis for targeted selective treatment of lambs post-weaning. Veterinary Parasitology, 258, 8-13. http://dx.doi.org/10.1016/j.vetpar.2018.06.001.

[18] Philcox, W., Garland, J., Zaidi, F., Morrow, P., Kesha, K., Stables, S., Wong, C. X., Spark, A., and Tse, R. (2018). Higher Heart Weight in New Zealand Māori and Pacific Islanders. The American Journal of Forensic Medicine and Pathology, 39, 208-212. http://dx.doi.org/10.1097/paf.0000000000000403.

[19] Kim, H., Hur, M., Choi, S. G., Oh, K. M., Moon, H. W., and Yun, Y. M. (2015). Comparison of white blood cell counts by WNR, WDF, and WPC channels in Sysmex XN hematology analyzer. International Journal of Laboratory Hematology, 37, 869-875. http://dx.doi.org/10.1111/ijlh.12421.

[20] Zhang, Y., Bai, J., Wu, H., and Ying, J. Y. (2015). Trapping cells in paper for white blood cell count. Biosensors \& bioelectronics, 69, 121-127. http://dx.doi.org/10.1016/j.bios.2015.02.019.

[21] Schwartz, C., Eberle, J. U., and Voehringer, D. (2016). Basophils in inflammation. European Journal of Pharmacology, 778, 90-95. http://dx.doi.org/10.1016/j.ejphar.2015.04.049.

[22] Liu, W. (2019). A mathematical model for the robust blood glucose tracking. Mathematical Biosciences and Engineering: MBE, 16, 759-781. http://dx.doi.org/10.3934/mbe.2019036.

[23] Triplitt, C. L. (2012). Understanding the kidneys' role in blood glucose regulation. The American Journal of Managed Care, 18, S11-16.

[24] Cánovas, R., Cuartero, M., and Crespo, G. A. (2019). Modern creatinine (Bio)sensing: Challenges of point-of-care platforms. Biosensors \& Bioelectronics, 130, 110-124. http://dx.doi.org/10.1016/j.bios.2019.01.048. 


\section{Supplementary}

$\mathbf{A}$

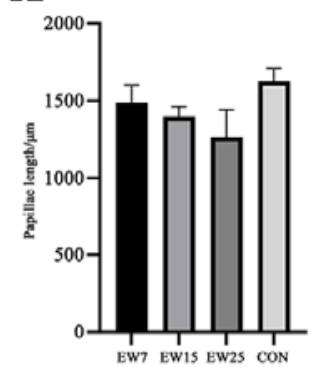

B

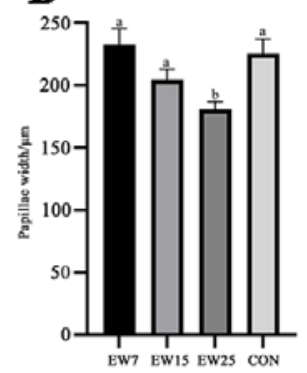

C

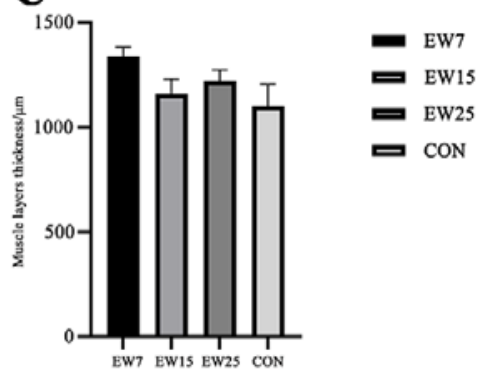

A: Rumen papillae length. B: Rumen papillae weigth. C: Rumen muscle thichness.

Figure S1. The comparison of rumen morphology.
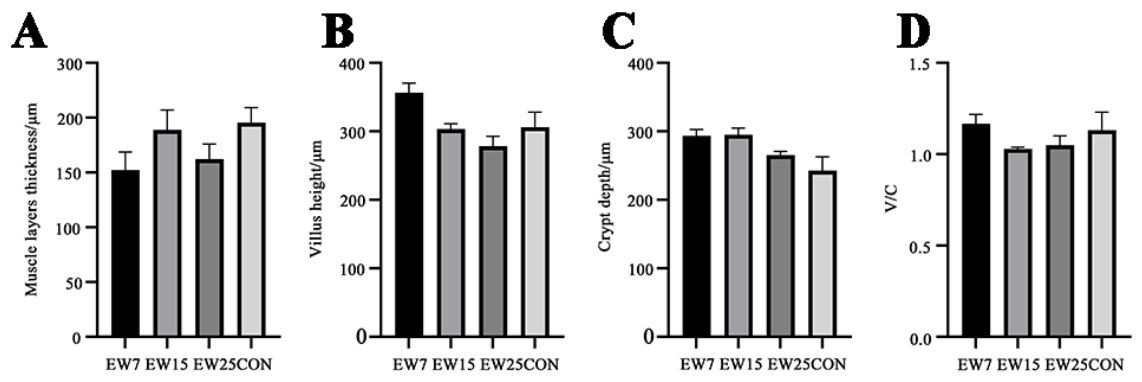

$$
\begin{aligned}
& \text { 口 }{ }^{\mathrm{EW} 7} \\
& \text { ㅌ15 } \\
& \text { 口 }{ }^{\mathrm{EW} 25} \\
& \text { 口 }{ }^{\mathrm{CON}}
\end{aligned}
$$

A: muscle layers thickness. B: villus height. C: crypt depth. D: VIC ratio

Figure S2. The comparison of duodenum morphology.
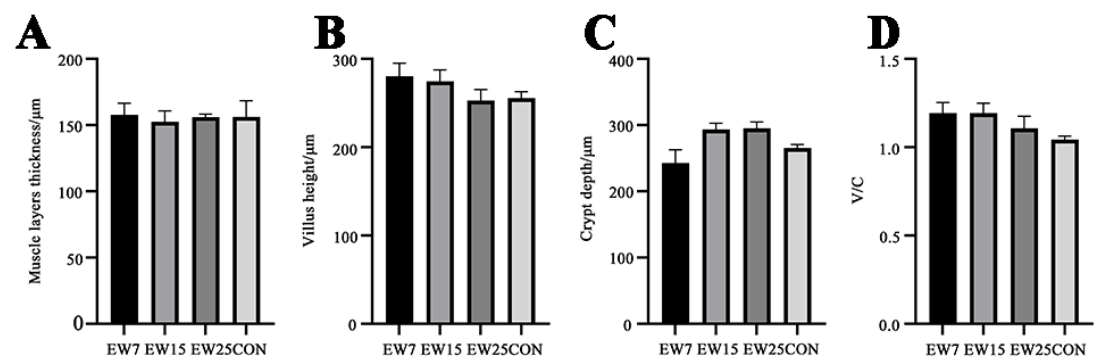

A: muscle layers thickness. B: villus height. C: crypt depth. D: VIC ratio

Figure S3. The comparison of jejunum morphology.
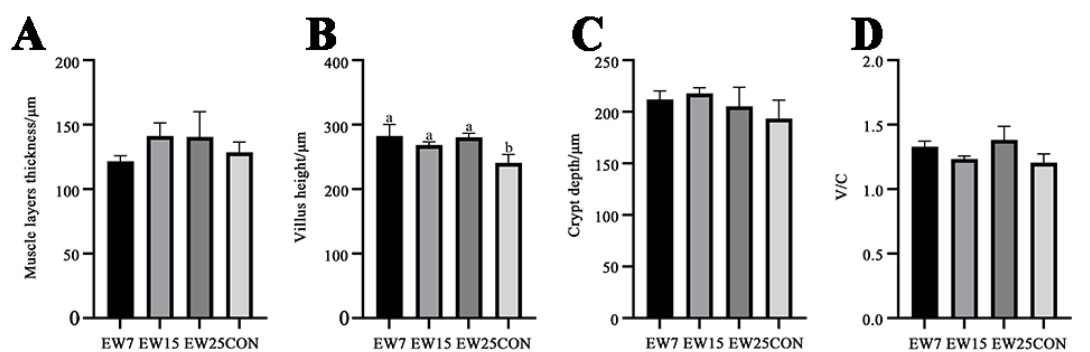

- Ew7

口 EW15

口 $\mathrm{EW} 25$

口 $\cos$

A: muscle layers thickness. B: villus height. C: crypt depth. D: V\C ratio

Figure S4. The comparison of ileum morphology. 